\title{
Los Ejercicios para las bestezuelas de Dios de Peñalosa y la doctrina de san Ignacio de Loyola
}

\section{The Ejercicios para las bestezuelas de Dios by Peñalosa and the doctrine of saint Ignacio de Loyola}

\author{
Fernando Arredondo Ramón \\ Universidad de Granada, España \\ farredo@gmail.com
}

Resumen: Desde un punto de vista de los contenidos y su sentido, abordaremos el modo en que Joaquín Antonio Peñalosa se ha podido inspirar en los Ejercicios espirituales de san Ignacio de Loyola para la elaboración de su obra poética Ejercicios para las bestezuelas de Dios, un libro cuyos protagonistas son animales o plantas, donde adapta a su lenguaje poético, especialmente al franciscanismo poético, el itinerario ignaciano para alcanzar la unión con Dios. Nuestro propósito es comparar ambos textos para hacer objetiva una relación que evoca el título de la obra peñalosiana, pero que aún no se había realizado de modo explícito. Del trabajo concluiremos que Peńalosa sigue parcialmente la misma estructura argumental que los Ejercicios de san Ignacio para lograr los mismos fines ascéticos, mostrando así la verosimilitud en la afirmación de que el libro del mexicano es poesía ascética de estilo franciscano, con raíces en san Ignacio.

Palabras clave: Joaquín Antonio Peñalosa, franciscanismo poético, poesía religiosa, Ejercicios espirituales, literatura mexicana. 
Abstract: From a point of view of the contents and its meaning, we'll approach the way in which Joaquín Antonio Peñalosa could have inspired himself on the Ejercicios espirituales of Saint Ignacio de Loyola by the elaboration of his poetic work Ejercicios para las bestezuelas de Dios, a book whose main characters are animals or plants, where he adapts to his poetic language, especially poetic Franciscanism, the Ignatian itinerary to reach the union with God. Our purpose is to compare both texts in order to make objective a relationship that recalls the title of the Peñalosian work, though that had not yet explicitly been done. From this work we will conclude that Peñalosa follows the same argument structure as the Ejercicios of Saint Ignacio to achieve the same ascetic aims, evidencing that the book of the Mexican is ascetic poetry of Franciscan style, with roots in saint Ignacio.

Keywords: Joaquín Antonio Peñalosa, Poetic franciscanism, Religious poetry, Spiritual exercises, Mexican literature.

Recibido: 12 de septiembre 2018

Aceptado: 13 de enero 2019

http://dx.doi.org/10.15174/rv.v0i24.425

\section{Objetivos y metodología}

Co obra poética de Joaquín Antonio Peńalosa es extensa, pero rentescos con otras poéticas, su inserción en el panorama literario de su época no son demasiado abundantes. Este trabajo pretende arrojar luz para la interpretación religiosa, en concreto católica, de uno de sus primeros poemarios, Ejercicios para las bestezuelas de Dios, que se editó por primera vez en 1951. Si bien el título sugiere su inspiración en los Ejercicios espirituales de san Ignacio de Loyola, queremos saber si el paralelismo va más allá del título y lo podemos encontrar también en el sentido e intenciones de los poemas que ahí se recogen. 
Para realizar el trabajo, nos hemos servido de la última versión de Ejercicios para las bestezuelas de Dios revisada por Peñalosa, que es la que se recoge en Hermana poesía, recopilación poética de 1997 editada por David Ojeda. En primer lugar vamos a indicar que Peńalosa escribe poemas-meditaciones protagonizadas por animales o seres de la naturaleza como expresión de su franciscanismo poético. A continuación vamos a ir estableciendo paralelismos de sentido entre los textos de Peńalosa y los de los Ejercicios de san Ignacio, relaciones cuya verosimilitud también nos la aportan externamente el enunciado del mismo título, coincidencias textuales entre ambos y el conocimiento teológico de Peñalosa de la doctrina católica evidenciada por sus ensayos al respecto (Arredondo, 2016: anexo 1). Lo haremos siguiendo el orden de aparición en el libro de poesía de Joaquín Antonio y buscaremos el texto ignaciano de similar mensaje.

De este modo, hacemos explícita, más allá de una vaga referencia en su título, la verdadera inspiración y sentido ascético de este libro del autor potosino. Lo cual nos parece interesante para insertar esta obra lírica en la corriente de poesía católica mexicana e hispanoamericana del siglo $\mathrm{xx}$, en concreto como un franciscanismo poético con presencia ignaciana, aunque no sea esta inserción el objetivo principal del trabajo, pues no se puede abordar de modo suficiente en un artículo de esta extensión. Indicar, pues, la fuente primera de Ejercicios para las bestezuelas de Dios, no sólo desde su título, sino desde los contenidos de ascética católica aquí desarrollados, es el propósito fundamental del trabajo. 


\section{Expresión del franciscanismo poético en Ejercicios para las bestezuelas de Dios}

La obra de Joaquín Antonio Peñalosa (San Luis Potosí, 19211999) es, sin duda, una de las más genuinas representantes del franciscanismo poético mexicano del siglo xx y una aportación imprescindible para la lírica religiosa hispanoamericana.

El concepto de franciscanismo poético en Peñalosa lo he desarrollado en el artículo "La semiótica de lo sencillo" en la revista Signa en el año 2016 (Arredondo, 2016: 385-412) y en parte de las aportaciones de otros autores entre los que se cuentan los siguientes: Miguel d'Ors, (2002) quien en su antología de poesía peñalosiana Un pequeño inmenso amor, dirá que

creo que es el amor, un amor general, de patente raigambre franciscana, la clave esencial de esas ondas de simpatía que irradia cada página de Peńalosa. Amor al Creador, tratado -véanse sobre todo los encantadores poemas en prosa del Diario del Padre Eternocon la entrañable confianza con que un niño pequeño 'se le sube a las barbas' a su padre, y -derivación natural de aquél- amor, rebosante de ternura, a todas las criaturas: a Nuestra Señora [...], a los ángeles, a la poesía -Hermana poesía se tituló precisamente su antología de 1997-, a los animales, omnipresentes en la poesía de Peñalosa [...]. Y, por supuesto, amor a los hombres, en especial a aquéllos a los que la Sagrada Escritura llama pobres: niños, ancianos, enfermos, indígenas, mujeres, emigrantes, víctimas de todo tipo... Leyendo los versos de Peñalosa uno se siente querido (d'Ors, 2002: 7-9).

David Ojeda, prologuista de Hermana poesía, dedica al menos cuatro páginas a hablar de san Francisco y de su doctrina para hablar de la poesía de Peñalosa (Ojeda, 1997: 9-12). También otro 
autor, Juan Manuel Martínez, dedica todo un capítulo de su obra Tres caminos y nueve voces en la poesía religiosa hispanoamericana a este asunto (Martínez Fernández, 2003: 366). Por último, Jiménez Cataño no escribe la palabra franciscanismo, pero hace alusión clara a este término cuando señala en la poesía de Peñalosa "una atención amorosa a las cosas pequeñas de la Naturaleza" (Jiménez Cataño, 2000: 42). González Salas (1960: 405) empleará este término para referirse a su obra en Antología mexicana de poesía religiosa.

Dios campa a sus anchas como un interlocutor directo del discurso peńalosiano y aparece como un ser querido y cercano, tratado desde la sencillez de un niño. Dios está en lo creado como su hacedor, pero también como su padre y en él están hermanadas todas las cosas, que reciben una luz especial que hace todo sea nuevo bajo el sol (Peñalosa, 1991: título).

Hasta tal punto encuentra la huella de Dios en cada una de sus criaturas (lo que no es sino una de las vías de santo Tomás) que incluso es capaz de proponer un poemario a modo de meditaciones, inspirado en los Ejercicios espirituales de san Ignacio, pero al modo franciscanista, protagonizado por animales fundamentalmente. Es decir, en lugar de meditar directamente sobre los misterios de la vida de Cristo presentes en el Evangelio (Loyola, 1977: 33) para alcanzar la visión de Dios, como hace el santo español, Peñalosa dirige su mirada a los misterios que es capaz de descubrir con su mirada de niño en sus criaturas, de las que se ha de tomar el ejemplo. Esta mirada a los misterios de la vida natural, le lleva directamente a la contemplación de Dios. Es, pues, una transformación a su manera de un libro clásico de ascética. Poetizar consejos ascéticos como el de guardar silencio o la práctica de la pobreza es una buena manera de actualizar una poética religiosa, vibrante y franciscanista y de atribuirle a la poesía una trascendencia inusual, incluso dentro del conjunto de su obra poética. Así, en lugar de 
meditar, por ejemplo, la muerte de Cristo, se medita la muerte de un árbol.

Establecer los paralelismos entre ambas obras y concretar este franciscanismo poético es el objetivo de este trabajo, como ya se dijo, y lo realizaremos someramente a continuación.

\section{Paralelismos entre Ejercicios para las bestezuelas de Dios} y Ejercicios espirituales

Ejercicios para las bestezuelas sigue, como es evidente incluso en su título, un esquema inspirado en los Ejercicios de san Ignacio. Ambos comienzan con un apartado llamado "Anotaciones". De hecho, el primer poema de Peñalosa se titula así, "Anotaciones", y ahí encontramos en los dos primeros versículos una cita de los Ejercicios ignacianos y una invocación explícita al santo español:

"Y las otras cosas sobre la faz de la tierra son criadas para el hombre y para que le ayuden en la prosecución del fin para que es criado"...

También las bestezuelas de Dios - ¡Oh Ignacio, oh Francisco! - pueden ayudarnos a ordenar vida y poesía.

Están unidas a la historia humana, a la historia divina desde la astuta víbora del Principio hasta el caballo apocalíptico.

Y es el Cordero - de Dios- el que quita el pecado del mundo (Peñalosa, 2007: 63).

El texto completo de san Ignacio, del que Peñalosa toma la cita, es el párrafo 23, que se titula "Principios y fundamentos":

El hombre es criado para alabar, hacer reverencia y servir a Dios nuestro Señor y, mediante esto, salvar su ánima; y las otras cosas sobre la haz de la tierra son criadas para el hombre, y para que le 
ayuden en la prosecución del fin para que es criado. De donde se sigue que el hombre tanto ha de usar dellas, quanto le ayudan para su fin, y tanto debe quitarse dellas, quanto para ello le impiden. Por lo qual es menester hacernos indiferentes a todas las cosas criadas, en todo lo que es concedido a la libertad de nuestro libre albedrío, y no le está prohibido; en tal manera, que no queramos de nuestra parte más salud que enfermedad, riqueza que pobreza, honor que deshonor, vida larga que corta, y por consiguiente en todo lo demás; solamente deseando y eligiendo lo que más nos conduce para el fin que somos criados" (Loyola, 1977: 7).

En prosa poética, Peñalosa va a realizar Ejercicios con los segundos medios de que dispone el hombre para acercarse a Dios: "las otras cosas sobre la faz de la tierra” (Peñalosa, 1997: 63). Concretamente va a establecer su foco sobre las bestias, porque "están unidas a la historia humana, a la historia divina desde la astuta víbora del Principio hasta el caballo apocalíptico" (Peñalosa, 1997: 63). De hecho, el mismo Cristo es un animal en este poema, aprovechando una imagen bíblica: "Y es el Cordero -de Dios- el que quita el pecado del mundo" (Peñalosa, 1977: 63).

Establecido así el primer paralelismo entre ambos libros, mencionaremos cómo aparece el franciscanismo poético en este primer poema. El hecho de que se fije en los animales como ejemplo de vida cristiana es, por supuesto, algo franciscanista, pero también lo es el hecho de que se fije en los medios secundarios, no en los principales, es decir, en los medios marginales, de los que apenas habla san Ignacio en sus Ejercicios, aunque reproduzca al comienzo el párrafo que ya hemos transcrito. Esto supone, a su vez, una primera diferencia entre ambos textos.

El segundo poema de Ejercicios para las bestezuelas de Dios se denomina "Preludios al arca de Noé", cuyo título está relacionado con los "preámbulos" presentes al inicio de cada uno de los capí- 
tulos de los Ejercicios de san Ignacio. Además, también hay una relación en los contenidos con el párrafo 20 de Ejercicios espirituales que dice así:

20ª La vigéssima: al que es más desembarazado y que en todo lo posible desea aprovechar, dénsele todos los exercicios spirituales por la misma orden que proceden; en los quales, por vía ordenada, tanto más se aprovechará, quanto más se apartare de todos amigos y conoscidos y de toda solicitud terrena; up como mudándose de la casa donde moraba, y tomando otra casa o cámera, para habitar en ella quanto más secretamente pudiere; de manera que en su mano sea cada día a missa y a vísperas, sin temor que sus conoscidos le hagan impedimiento. Del qual apartamiento se siguen tres provechos principales, entre otros muchos: el primero es, que en apartarse hombre de muchos amigos y conoscidos y, asimismo, de muchos negocios no bien ordenados, por servir y alabar a Dios nuestro Señor, no poco meresce delante su divina majestad; el segundo, estando ansí apartado, no teniendo el entendimiento partido en muchas cosas, mas poniendo todo el cuidado en sola una, es a saber, en servir a su Criador, y aprovechar a su propia ánima, usa de sus potencias naturales más libremente, para buscar con diligencia lo que tanto desea; el 3, quanto más nuestra ánima se halla sola y apartada, se hace más apta para se acercar y llegar a su Criador y Señor; y quanto más así se allega, más se dispone para rescibir gracias y dones dela su divina y summa bondad (Loyola, 1977: 6).

Lo mismo que san Ignacio propone en este párrafo la conveniencia de apartarse de los quehaceres habituales para centrar la atención en los temas de las meditaciones y en la vida de Cristo, es decir, para recogerse en Dios, es lo que hace Peńalosa en su poema: hablar del apartamiento del mundo, de las cosas mundanas, cons- 
truyendo un arca - un arca que construiría un niño, de cáscaras de nuez y naranjas-, como la del personaje bíblico, para quedarse solo y en la soledad del mar. Una soledad dulce (de azúcar) y tranquila (remanso), ni agobiante ni ajetreada, tal y como propone el texto de los Ejercicios espirituales anteriormente transcrito. El de Peñalosa dice así:

Como Noé me construiré mi arca con paredes de nuez y piso de naranja.

Lo encenderé con tres verdes luciérnagas, pintaré sus muros con anilinas de libélula.

Y en mar de azúcar quedará flotando su lento cabeceo de arrullos en remanso (Peñalosa, 1997: 64).

A continuación, como una declaración de intenciones, llama a los animales para que le ayuden a encontrarse con Dios (el Amor ${ }^{1}$ ) en ese retiro, y lo hace con la ayuda de los ángeles, los que aparecen en un vocativo sencillo, sin ceremonias ni oraciones rituales, con la llaneza del niño. La contemplación de Dios como Amor es el objeto de la meditación: "Al llamarlos, vendrán los animales. I Ayudadme a llamar, coros de ángeles" (Peñalosa, 1997: 64).

${ }^{1}$ Dios es ese Amor con letra capital que aparece en el último verso del poema y cuyo referente aparece nombrado en el verso anterior de este pareado: Dios. Y sus características son las que aparecen en las estrofas centrales: eterno ("Primero tú, amor constante que empiezas / siempre sin tener ocaso"), joven (“ $\mathrm{O} O \mathrm{O}$ verde limón! ¡Amor que no madura!”), espiritual (“Tú no vendrás, amor de noche con amor de carne"), ligero y veloz ("Hay amor con alas. ¡Ay, amor con alas!") y alegre ("Alegría del venadito de la serranía. / El amor sabe de sed y de sonrisa"). Además, la presencia de Dios en estas realidades de la naturaleza nos remite a las preguntas a las criaturas del Cántico espiritual de san Juan de la Cruz. 
Tras meditar sobre el amor de Dios, explicado con metáforas animales (gato con los pies de trapo, pájara pinta, víbora del mar, palomitas, venadito de la serranía, toro toronjil),

\section{[...] Primero tú, amor constante que empiezas}

siempre sin tener ocaso.

Este era un gato con los pies de trapo.

¡Oh verde limón! ¡Amor que no madura!

Que venga la pájara pinta pintada de dudas.

Y que pase el amor que no sabe detenerse.

La víbora de la mar, ¿de dónde viene?

Tú no vendrás, amor de noche con amor de carne;

coyote del gallinero, que tu amor naufrague.

Ángeles del sueño, acostadle.

Alegría de las palomitas que bajan a beber agua.

Hay amor con alas. jAy, amor con alas!

Alegría del venadito de la serranía.

El amor sabe de sed y de sonrisa.

Ángeles, que no se extinga.

Alegría de la huerta del toro toronjil:

el amor abre la rosa, el amor cierra el clavel

(Peñalosa, 2007: 64-65)

Cierra el poema con unos puntos suspensivos que expresan el desarrollo del retiro o, metafóricamente, el viaje en el arca, a solas con Dios, quien ha de dirigir el rumbo de la vida: "Viejo Padre 
Noé, cuando Dios entre, / ciérrame el arca y que el Amor navegue..." (Peñalosa, 1997: 64).

Así, concluimos los paralelismos entre el segundo poema de Peñalosa y el párrafo 20 de los Ejercicios espirituales.

Otro poema de Ejercicios para las bestezuelas continúa profundizando en la necesidad del retiro, en concreto del silencio de ese retiro, que los Ejercicios espirituales aconsejan para un mejor recogimiento. Es "Lección del caracol sobre el silencio". De nuevo un protagonista del mundo animal y una serie de imágenes tomadas de la pequeñez del caracol, ${ }^{2}$ convertido en un anacoreta que lleva su celda a cuestas.

Concluidos los preámbulos y avisos sobre cómo realizar el retiro y cuáles son sus fines, ${ }^{3}$ se debe meditar sobre la muerte y el infierno, según el santo fundador de la Compañía de Jesús.

Lo mismo hace Peñalosa con tres de sus poemas: meditar sobre la muerte, aunque no sobre el infierno, pues su visión esperanzada y optimista, confiada en la paternidad de Dios, no contempla la perdición de los que son hijos de Dios (no es que no crea en ella, es que chocaría de pleno con su poética). Los poemas para la consideración de la muerte son, por este orden de aparición, "Esquela del árbol. Composición de lugar" (Peñalosa, 1997: 66), en la que la muerte adquiere sentido con la muerte de Cristo:

Los ángeles del camino lo participamos con profundo dolor: ayer, a la hora verde, murió un árbol del camino. [...]

${ }^{2}$ Apuntaremos que la imaginería peñalosiana va evolucionando, y en estos poemas de sus orígenes poéticos está muy presente una imagen surrealista más hermética, como "el mar puede astillar las nubes / y enrojecer de cólera a las perlas". ${ }^{3}$ Peñalosa también sigue ese orden: se debe de hacer recogido y en silencio, y su finalidad es encontrarse con Dios para que actúe en el alma, para que coja sus riendas. 
Como el árbol de Dios en el Calvario, todo árbol se sabe nacido y mortal. ¡Oh ángel, árbol sin tronco y sin semilla! (Peñalosa, 1997: 66).

Y donde se considera que Dios es un leñador que toma sus criaturas para encender un fuego en el cielo: "El duelo se despide tal vez en una estrella; tal vez el Leñador lo necesite para prender sus fogatas celestiales" (Peñalosa, 1997: 66).

Los otros dos poemas son "Meditaciones a las mariposas sobre la muerte" (Peñalosa, 1997: 68), donde el escritor medita sobre la brevedad de la vida y la banalidad de las cosas materiales consideradas a la luz de la muerte, y "Consolación por el asnillo muerto" (Peñalosa, 1997: 77) donde el potosino considera la inevitable presencia de la cruz (el sacrificio) en la vida y la muerte en esa cruz.

El siguiente asunto que se trata en Ejercicios para las bestezuelas es la contemplación de lo inmensamente grande en lo aparentemente pequeño. Esto se percibe en el poema "La mariposa nos advierte que pequeñez es grandeza” (Peñalosa, 1997: 70). Es verosímil su correspondencia con la contemplación del Nacimiento de Jesús, desde el párrafo 110 en adelante de los Ejercicios. En este se dice:

[114] $1^{\circ}$ puncto. El primer puncto es ver las personas, es a saber, ver a nuestra Señora y a Joseph y a la ancila y al niño Jesú después de ser nascido, haciéndome yo un pobrecito y esclavito indigno, mirándolos, contemplándolos y sirviéndolos en sus neccessidades, como si presente me hallase, con todo acatamiento y reverencia posible; y después reflectir en mí mismo para sacar algún provecho (Loyola, 1977: 18).

Toda la divinidad contenida en un bebé. Eso es lo que cualquiera supondría que se ha de contemplar en esa escena evangélica. Del 
mismo modo, Peñalosa anuncia la grandeza de Dios, expresada en una simple mariposa: "tu inmensa pequeñez que el aire afina / y apenas puede sostenerte el mundo".

Contemplada la grandeza de un Dios Niño, se medita ahora sobre la virtud de la pobreza, una virtud muy querida por Francisco de Asís, y comentada por Ignacio de Loyola en Ejercicios en muchos capítulos de su obra, de los que reproducimos tan sólo un texto por evidentes exigencias de espacio:

[357] 5a regla. La quinta: alabar votos de religión, de obediencia, de pobreza, de castidad y de otras perfectiones de supererogación; y es de advertir que como el voto sea cerca las cosas que se allegan a la perfección evangélica, en las cosas que se alejan della no se debe hacer voto, así como de ser mercader o ser casado, etcétera (Loyola, 1977: 47).

Esta virtud de la pobreza la trata Peñalosa en "Ejemplo del caracol en la santa pobreza” (Peńalosa, 1997: 75). Esta pequeńa criatura, ya descrita anteriormente como un ermitaño, no tiene nada, sólo su concha-celda:

[...] Te tiendes en tu celda solo y pobre ahorrando espacio por ganar sosiego; como los pobres ruedas por el mundo, viejo sistema de medir suelo.

Si tu tanque blindado movilizas, un centímetro crece el universo (Peñalosa, 1997: 75).

Otro asunto presente en ambos libros aparece en el "Coloquio de los elefantes" (Peñalosa. 1997: 71), que vendría a ser una reflexión sobre las malas inclinaciones que de nacimiento los hombres adquieren por el pecado original, según es doctrina de la Igle- 
sia Católica, haciendo metáfora con el mal aspecto que tienen los elefantes, ya arrugados desde su nacimiento -"Nos vimos arrugados y éramos recién nacidos, / la piel como libreta inservible de un niño" (Peńalosa, 1997: 71)-. Los elefantes, como los pecadores, están lejos de su tierra, como el destierro en el valle de lágrimas que es el mundo para la mentalidad católica - “ $\mathrm{O}$ cielo lejos y tierra en lejanía” (Peñalosa, 1997: 71)-. Además, los elefantes, conscientes de su situación, piden perdón a Dios, con el Kyrie eleison - “`Por qué si somos tristes se ríen de nosotros? / Creador del elefante, ten piedad de nosotros" (Peñalosa, 1997: 71)-. Las referencias a las malas inclinaciones de la naturaleza humana consecuencia del pecado aparecen en distintas ocasiones, expresadas como limitaciones, padecimientos y enredos - "Y las patas se enredan quebrando las gardenias/y asustamos la fuente en el concilio de estrellas. / Líbranos del cirquero que nos trae muertos de hambre / y del parque zoológico pequeño y elegante" (Peñalosa, 1997: 71)-. Todo esto se trata, evidentemente, de modo mucho más prosaico y pragmático en los Ejercicios espirituales cuando se habla del pecado a partir del párrafo 244, aunque lo hace también incluyéndolo en muchos otros capítulos.

También aparece el envío a la misión evangélica, expresado en el "Sermón a los peces". Hay una predicación a animales, como la que hacía san Francisco. En este caso a los peces, puesto que ellos fueron escogidos por el mismo Cristo en el Evangelio para expresar la misión de los Apóstoles: pescar. El asunto del envío apostólico aparece en el párrafo 281: "De cómo los apóstoles fueron embiados a predicar escribe Sant Matheo, capítulo X, v. 1-16" (Loyola, 1977: 37).

Amados hermanos en Nuestro Señor Jesucristo: en el nombre del Padre, que es vuestro criador; de Rafael arcángel, viajero y pescador, 
santígüense las frentes, oigan con atención, redondo el ojo quieto, quietud del corazón (Peñalosa, 1997: 73).

Por último, Peñalosa escribe "Consideración de las hormigas para alcanzar el amor” (Peñalosa, 1997: 79), que tendría correspondencia con el capítulo de los Ejercicios de san Ignacio "Contemplación para alcanzar amor”, en el párrafo 230. En este poema Peñalosa despliega una gran imaginería franciscanista, como comentamos anteriormente en este mismo capítulo, para considerar la unión mística basada en la filiación divina, como se deduce de los versos: "Pero Tú nos creaste en los últimos segundos de los Siete Días. / ¡Pero tenemos vida!...” (Peñalosa, 1997: 79).

Entonces: necesidad del retiro y el silencio para el encuentro con Dios, meditación sobre la muerte, contemplación de Dios Niño, la virtud de la pobreza o desprendimiento de los bienes materiales, reflexión sobre las malas inclinaciones de la naturaleza humana herida por el pecado original, el envío apostólico, y la unión amorosa con Dios son los asuntos coincidentes, entre ambas obras, cuyos fines parecen ser los mismos, aunque su expresión es de prosa didáctica en el caso de san Ignacio y de verso lírico en el caso de Peñalosa.

Debemos de tener en cuenta que, evidentemente, el poemario de Peñalosa es bastante más breve que los Ejercicios de san Ignacio, así que hay muchos temas recogidos aquí que no se mencionan en el libro de Peñalosa. 


\section{Los Ejercicios de Peñalosa en la poesía religiosa hispanoamericana}

El franciscanismo poético de Peñalosa consigue ser el hilo conductor de toda su obra poética en un diálogo, con Dios y con el otro, sobre las realidades más íntimas y vitales del hombre y de la mujer (mexicanos y de todos los lugares del mundo), siempre con una perspectiva trascendente, con el horizonte situado en la vida eterna de la tradición judeocristiana. Esta reflexión dialogada, más o menos explícita, acerca de las verdades últimas y del sentido de la vida se encuentra en una dimensión religiosa que ya hemos encontrado en no pocos autores mexicanos contemporáneos de Peñalosa y en otros de las letras hispanoamericanas, como Ernesto Cardenal o Ibánez Langlois ${ }^{4}$ entre muchísimos otros. La relación entre Cardenal y Peńalosa ya quedó planteada en otro de mis trabajos (Arredondo, 2016b: 225 y 267); la de Ibáñez Langlois con Peñalosa la conocemos por Rafael Jiménez Cataño, quien dejó el siguiente testimonio en Istmo: "José Miguel Ibáńez Langlois me hizo notar hace años que Peñalosa era admirable por su modo ágil, informal y juguetón de abordar poéticamente lo sacro, género que durante tantos siglos se ha encomendado al estilo solemne" (2000: 40).

${ }^{4}$ La conexión entre estos dos autores la encontramos no sólo en la religiosidad dentro de la más pura ortodoxia católica de sus poesías, sino en algunas imágenes empleadas como el viento (imagen del pecado cuya realidad y poder sobre Cristo es efímero y volátil, aunque ruidoso), en las llagas de Cristo resonando en Copa del mundo y en el Libro de la pasión; por ejemplo: "cruza el viento aullando por el hueco de los clavos" (Peñalosa, 1997: 338) y "silbar así no más entre sus propios huesos" (Ibáńez Langlois, 1987: 84), son dos versos -entre tantos otros- donde aparece esta imagen. En general, el libro citado de Ibáñez Langlois y Copa del mundo de Peńalosa tienen puntos en común evidentes ante los ojos de cualquiera (ya Jiménez Cataño dijo que el Libro de la Pasión fue el detonante de Copa del mundo). 
Uno de los grandes logros de Peñalosa es haber escrito una poesía desde la ortodoxia católica, pero alejada de los estereotipos y clichés piadosos tradicionales de este tipo de poesía. La cosmovisión peñalosiana descompone el mundo en un sinfín de pequeñas realidades vistas desde una perspectiva innovadora y optimista (luminosa, podríamos decir) que adquieren sentido integrándose en el plan de Dios, un plan que se manifiesta en el orden natural y que afecta a todo el universo. Podríamos concluir, por tanto, que Peñalosa transcribe al franciscanimo poético la prosa ascética de san Ignacio, aportando así una original e interesante obra a la lírica religiosa hispanoamericana tan abundante en el siglo $\mathrm{xx}$.

\section{Bibliografía}

Arredondo Ramón, Fernando, 2016, "La semiótica de lo sencillo en Joaquín Antonio Peñalosa”, Signa, núm. 25, pp. 385-412. , 2016b, Joaquín Antonio Peñalosa en la tradición poética mexicana, Universidad de Granada, Granada. Disponible en: http://digibug.ugr.es/handle/10481/40651

D’Ors, Miguel, 2002, Un pequeño inmenso amor, Cuatro Estaciones, Lucena.

González Salas, Carlos, 1960, Antología mexicana de poesía religiosa, Jus, México.

Ibáńez Langlois, José Miguel, 1987, Libro de la Pasión, Rialp, Madrid.

Jiménez Cataño, Rafael, 2000, "Peñalosa: poeta y otras maravillas”, Istmo, núm. 247, marzo, pp. 40-43.

Loyola, Ignacio de, 1977, Ejercicios espirituales, Ediciones Cristo Rey, Rosario. 
Martínez Fernández, Juan Manuel, 2003, Tres caminos y nueve voces en la poesía religiosa hispanoamericana, Universidad Complutese, Madrid. Disponible en: http://eprints.ucm.es/3993/.

Ojeda, David (ed.), 1997, Hermana poesía, Editorial Ponciano Arriaga, San Luis Potosí.

Peñalosa, Joaquín Antonio, 1997, Hermana poesía, David Ojeda (ed.), Editorial Ponciano Arriaga, San Luis Potosí. 1991, "Todo es nuevo bajo el sol", en La vida tiene siete colores, Ediciones Paulinas, México, pp. 16-17. 